\title{
Follicle-stimulating hormone (FSH) activities of some synthesized isoxazole and pyrazoline derivatives.
}

\author{
Ahmed A. Fayed ${ }^{1,2 *}$, Saleh A. Bahshwan ${ }^{3}$, Randa E. Abde-Megeid ${ }^{2}$, Mohammad E. Azab ${ }^{4}$, Abd El- \\ Galil E. Amr 5,6, Mohamed M. Abdalla ${ }^{7}$ \\ ${ }^{1}$ Respiratory Therapy Department, Taibah University, Madinah Munawara, Saudi Arabia \\ ${ }^{2}$ Photochemistry Department, National Research Center, Cairo, Dokki, Egypt \\ ${ }^{3}$ Pharmacology and Toxicology Department, College of Pharmacy, Taibah University, Madina Munawarah, Saudi \\ Arabia \\ ${ }^{4}$ Chemistry Department, Faculty of Science, Ain Shams University, Abbassia, Cairo, Egypt \\ ${ }^{5}$ Pharmaceutical Chemistry Department, Drug Exploration and Development Chair (DEDC), College of Pharmacy, \\ King Saud University, Riyadh, Saudi Arabia \\ ${ }^{6}$ Applied Organic Chemistry Department, National Research Center, Cairo, Dokki, Egypt \\ ${ }^{7}$ Atos Pharma, Elkatyba Land, Belbis, ElSharkya, Egypt
}

\begin{abstract}
A novel series of arylidiene, isoxazole, pyrazolines, and their derivatives 2-8 were synthesized by using estrone (3-hydroxyestran-17-one, 1) as starting material. Some of the synthesized compounds were screened as follicle-stimulating hormone (FSH) agents. The synthesized compounds were illustrated by elemental analysis and spectroscopic evidences.
\end{abstract}

Keywords: Estrone derivatives, Isoxazoles and pyrazolines, Follicle-stimulating hormone activities.

Accepted on September 21, 2018

\section{Introduction}

Heterocyclic compounds are well known to possess pharmacological activities. Some of these derivatives were reported as biological and pharmacological [1], antifungal [2,3], antiinflammatory [4,5], antiamebic [6], antimicrobial $[7,8]$, and antiasthma [9] agents. In previous work we have reported that certain of substituted pyrazole and oxazole heterocycles represent class of compounds that play an important role in the medicinal chemistry. Previously we have reported the SARS-CoV 3C-like protease inhibitors [10], against different cancer cell lines [11-13], EGFR and VEGFR-2 kinase inhibitors [14] activities for different series of substituted pyrazole derivatives. On the other hand, the oxazole heterocyclic derivatives have effective pharmacological importance. For example, a large number of nitrogen atoms are interesting drug candidates including potential analgesic and anti-convulsant [15], androgenic anabolic activities $[16,17]$. In view of these observations and in continuation of our studies in heterocyclic chemistry [18-21], we screened some of synthesized of fused isoxazole and pyrazoline compounds with estrone ring as follicle-stimulating hormone (FSH) agents.

\section{Materials and Methods}

\section{Chemistry}

All melting points are uncorrected and were measured using an electro thermal capillary melting point apparatus. The IR spectra were recorded on a Shimadzu FT-IR 8101 PC infrared spectrophotometer. The $1 \mathrm{H}$ and ${ }^{13} \mathrm{C}-\mathrm{NMR}$ spectra were determined with bruker $600 \mathrm{mhz}$ NMR spectrometer by using $\mathrm{CDCl}_{3}$ as solvent. The chemical shifts are expressed on the $\delta$ (ppm) scale using TMS as the standard reference. Mass spectra were recorded on Finnigan SSQ operating at $70 \mathrm{ev.} \mathrm{Elemental}$ analysis determined on a Perkin Elmer 240 (microanalysis), Microanalysis Center, Cairo University, Cairo, Egypt.

\section{Synthesis of 3-hydroxy-16-((aryl) methylene)- estra-1(10), 2, 4-trien-17-one (2a and 2b)}

A solution of $1(0.54 \mathrm{~g}, 20 \mathrm{mmol})$ and the corresponding aromatic aldehydes, namely, benzaldehyde or 4pyridinecarbaldehyde $(20 \mathrm{mmol})$ in a mixture of ethanol $(50$ $\mathrm{ml})$ and aqueous potassium hydroxide $(10 \mathrm{ml}, 30 \%)$ was stirred over night at room temperature. The separated solid product 
was filtered off, washed with water and crystallized from ethanol to give compounds $2 \mathrm{a}$ and $2 \mathrm{~b}$ respectively.

3-hydroxy-16-((phenyl) methylene) estra-1(10), 2, 4trien-17-one (2a): Yield 98\%, mp $258-260^{\circ} \mathrm{C},(\alpha)^{25} \mathrm{D}^{=+117}$ $\left(\mathrm{c}_{1}, \mathrm{MeOH}\right)$. IR spectrum, $v, \mathrm{~cm}^{-1}: 3341(\mathrm{OH}), 3060$ and 3048 (CH, Ar), 2943 (CH, aliphatic), $1746(\mathrm{C}=\mathrm{O}), 1644(\mathrm{C}=\mathrm{C}) .{ }^{1} \mathrm{H}$ NMR spectrum, $\delta$, ppm: 0.64-60 m $(1 \mathrm{H}, \mathrm{H}-8 \beta), 0.92-0.90 \mathrm{~s}$ $\left(3 \mathrm{H}, \mathrm{CH}_{3}\right), 1.03-1.00 \mathrm{~m}(1 \mathrm{H}, \mathrm{H}-11 \beta), 1.12-1.10 \mathrm{~m}(1 \mathrm{H}, \mathrm{H}-7 \alpha)$, 1.16-1.14 m (1H, H-12 $\alpha), 1.26-1.24 \mathrm{~m}(1 \mathrm{H}, \mathrm{H}-14 \alpha), 1.42-1.40$ $\mathrm{m}(1 \mathrm{H}, \mathrm{H}-15 \beta), 1.59-1.55 \mathrm{~m}(1 \mathrm{H}, \mathrm{H}-15 \alpha), 1.73-1.70 \mathrm{~m}(1 \mathrm{H}$, $\mathrm{H}-7 \beta)$, 2.04-2.00 m (1H, H-9 $\alpha), 2.10-2.08 \mathrm{~m}(1 \mathrm{H}, \mathrm{H}-11 \alpha)$,

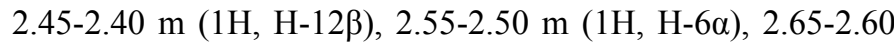
m $(1 \mathrm{H}, \mathrm{H}-6 \beta), 4.97 \mathrm{~s}\left(1 \mathrm{H}, \mathrm{OH}\right.$, exchangeable with $\left.\mathrm{D}_{2} \mathrm{O}\right), 6.74$ dd (1H, H-2), $6.67 \mathrm{~d}(1 \mathrm{H}, \mathrm{H}-4), 6.71 \mathrm{~s}(1 \mathrm{H}$, arylidene proton), $7.10 \mathrm{~d}(1 \mathrm{H}, \mathrm{H}-1), 7.28-7.48 \mathrm{~m}(5 \mathrm{H}, \mathrm{Ar}-\mathrm{H}) .{ }^{13} \mathrm{C}$ NMR spectrum, $\delta$, ppm: 13.80, 21.55, 25.93, 26.42, 29.51, 36.53, 38.34, 43.94, $48.09,50.48,108.09,112.84,115.26,125.80,126.40,126.50$, 126.53, 132.89, 135.92, 138.11, 153.55, 164.88, 210.12 (25 C). MS (EI): m/z $358(100 \%)\left(\mathrm{M}^{+}\right)$. Found, \%: C 83.68; H 7.24. $\mathrm{C}_{25} \mathrm{H}_{26} \mathrm{O}_{2}$ (358.47). Calculated, \%: C 83.76; H 7.31.

3-hydroxy-16-((4-pyridyl) methylene) estra-1 (10), 2, 4trien-17-one (2b): Yield $90 \%$, mp $200-202^{\circ} \mathrm{C},(\alpha)^{25} \mathrm{D}=+101$ (c1, MeOH). IR spectrum, $v, \mathrm{~cm}^{-1}: 3340(\mathrm{OH}), 3062$ and 3044 (CH, aromatic), $2943(\mathrm{CH}$, aliphatic), $1743(\mathrm{C}=\mathrm{O}), 1641$ $(\mathrm{C}=\mathrm{C}) .{ }^{1} \mathrm{H}$ NMR spectrum, $\delta$, ppm: 0.61-0.58 m $(1 \mathrm{H}, \mathrm{H}-8 \beta)$, $0.91 \mathrm{~s}\left(3 \mathrm{H}, \mathrm{CH}_{3}\right), 1.03-1.00 \mathrm{~m}(1 \mathrm{H}, \mathrm{H}-11 \beta), 1.11-1.08 \mathrm{~m}(1 \mathrm{H}$, $\mathrm{H}-7 \alpha)$, 1.16-1.14 m (1H, H-12 $\alpha), 1.27-1.25 \mathrm{~m}(1 \mathrm{H}, \mathrm{H}-14 \alpha)$,

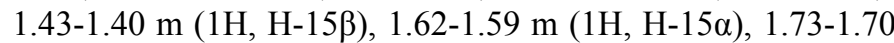
$\mathrm{m}(1 \mathrm{H}, \mathrm{H}-7 \beta), 2.03-2.00 \mathrm{~m}(1 \mathrm{H}, \mathrm{H}-9 \alpha), 2.08-2.06 \mathrm{~m}(1 \mathrm{H}$, $\mathrm{H}-11 \alpha), 2.46-2.43 \mathrm{~m}(1 \mathrm{H}, \mathrm{H}-12 \beta), 2.54-2.51 \mathrm{~m}(1 \mathrm{H}, \mathrm{H}-6 \alpha)$, 2.66-2.64 m (1H, H-6 3$), 4.98 \mathrm{~s}(1 \mathrm{H}, \mathrm{OH}$, exchangeable with $\left.\mathrm{D}_{2} \mathrm{O}\right), 5.79 \mathrm{dd}(1 \mathrm{H}, \mathrm{H}-2), 6.69 \mathrm{~d}(1 \mathrm{H}, \mathrm{H}-4), 6.72 \mathrm{~s}(1 \mathrm{H}$, arylidene proton), $7.11 \mathrm{~d}(1 \mathrm{H}, \mathrm{H}-1), 7.35-7.88 \mathrm{~m}(4 \mathrm{H}, \mathrm{Ar}-\mathrm{H})$. ${ }^{13} \mathrm{C}$ NMR spectrum, $\delta$, ppm: 13.85, 21.73, 25.83, 26.44, 29.55, $36.55,38.44,43.99,48.25,50.62,108.22,112.83,115.35$, $124.22,126.43,132.33,138.51,147.17,149.62,153.64$, 164.85, 210.34 (24 C). MS (EI): m/z 359 (100\%) $\left(\mathrm{M}^{+}\right)$. Found, \%: C 80.10; H 6.94; N 3.82. $\mathrm{C}_{24} \mathrm{H}_{25} \mathrm{NO}_{2}$ (359.46). Calculated, $\%$ : C 80.19; H 7.01; N 3.90 .

\section{Synthesis of 3-hydroxy-16-(phenyl-(aryl) methane) estra-1 (10), 2, 4-trien-17-one (3a and 3b)}

Preparation of phenylmagnesium bromide: Weigh $6 \mathrm{mmol}$ of magnesium turnings in one test tube and in another test tube mix $6 \mathrm{mmol}$ of bromobenzene $1 \mathrm{ml}$ of anhydrous diethyl ether. Transfer the content of the second tube to the first portion wise with sonication.

Addition of the grignard: In Erlenmeyer flask dissolve (4 mmol) of compound 2 in $20 \mathrm{ml}$ of anhydrous diethyl ether and place in an ice-bath over a stirring motor. Stir the resulting solution slowly, and then use a Pasteur pipette to slowly transfer the Grignard reagent to the cold solution drop wise. Once the addition of the Grignard reagent is complete, remove the flask from the ice-bath and let it stir at room temperature for about 5-10 min (during this time you should begin to chill 5 $\mathrm{ml}$ of $5 \% \mathrm{H}_{2} \mathrm{SO}_{4}$ for the next step of the experiment). To quench the reaction, slowly add $5 \mathrm{ml}$ of chilled $5 \% \mathrm{H}_{2} \mathrm{SO}_{4}$ (aq.) to the reaction flask (continue to stir, if possible). Transfer the reaction mixture to separatory funnel, leaving behind any undissolved solids then takes the ether layer then wash it with $3 \mathrm{ml}$ of saturated aqueous sodium chloride. Collect the ether solution, dry it over anhydrous sodium sulfate, and evaporate to dryness and crystallized from methanol to give compounds $3 \mathrm{a}$ and $3 \mathrm{~b}$, respectively.

3-hydroxy-16-(bisphenyl-methane)-estra-1 (10), 2, 4trien-17-one (3a): Yield 44\%, mp $212-214^{\circ} \mathrm{C},(\alpha)^{25}{ }_{\mathrm{D}}=+107$ (c1, MeOH). IR spectrum, $v, \mathrm{~cm}^{-1}: 3344(\mathrm{OH}), 3065$ and 3043 (CH, aromatic), 2944 (CH, aliphatic), $1735(\mathrm{C}=\mathrm{O}), 1645$

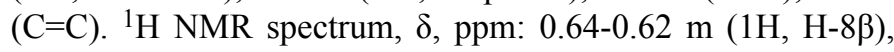
0.92-0.90 s (3H, $\left.\mathrm{CH}_{3}\right), 1.03-1.00 \mathrm{~m}(1 \mathrm{H}, \mathrm{H}-11 \beta), 1.13-1.10 \mathrm{~m}$ $(1 \mathrm{H}, \mathrm{H}-7 \alpha), 1.17-1.15 \mathrm{~m}(1 \mathrm{H}, \mathrm{H}-12 \alpha), 1.25-1.22 \mathrm{~m}(1 \mathrm{H}$, $\mathrm{H}-14 \alpha), 1.40-1.38 \mathrm{~m}(1 \mathrm{H}, \mathrm{H}-15 \beta), 1.57-1.55 \mathrm{~m}(1 \mathrm{H}, \mathrm{H}-15 \alpha)$,

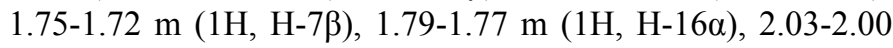
$\mathrm{m}(1 \mathrm{H}, \mathrm{H}-9 \alpha), 2.07-2.05 \mathrm{~m}(1 \mathrm{H}, \mathrm{H}-11 \alpha), 2.32 \mathrm{~s}(1 \mathrm{H}$, phenylCH-phenyl), 2.46-2.43 m (1H, H-12 $\beta), 2.56-2.54 \mathrm{~m}(1 \mathrm{H}$, $\mathrm{H}-6 \alpha), 2.65-2.62 \mathrm{~m}(1 \mathrm{H}, \mathrm{H}-6 \beta), 4.98 \mathrm{~s}(1 \mathrm{H}, \mathrm{OH}$, exchangeable with $\left.\mathrm{D}_{2} \mathrm{O}\right), 5.78 \mathrm{dd}(1 \mathrm{H}, \mathrm{H}-2), 6.68 \mathrm{~d}(1 \mathrm{H}, \mathrm{H}-4), 7.11 \mathrm{~d}(1 \mathrm{H}$, $\mathrm{H}-1), 7.30-7.58 \mathrm{~m}(10 \mathrm{H}, \mathrm{Ar}-\mathrm{H}) .{ }^{13} \mathrm{C}$ NMR spectrum, $\delta$, ppm: $13.83,21.47,25.56,26.45,29.31,36.63,38.66,43.94,47.55$, $48.47,50.47,58.13,112.80,115.34,125.80,126.40,126.50$, $126.55,126.90,128.50,130.20,132.89,135.92,138.14$, 145.40, 153.89, 218.55 (31 C). MS (EI): m/z $436(100 \%)\left(\mathrm{M}^{+}\right)$. Found, \%: C 85.18; $\mathrm{H}$ 7.33. $\mathrm{C}_{31} \mathrm{H}_{32} \mathrm{O}_{2}$ (436.58). Calculated, $\%$ C 85.28; H 7.39.

3-hydroxy-16-(phenyl-(4-pyridyl)-methane)-estra-1 (10), 2, 4trien-17-one (3b): Yield $35 \%$, m.p. $230-232^{\circ} \mathrm{C},(\alpha)^{25} \mathrm{D}^{=+156}$ (c1, MeOH). IR spectrum, $v, \mathrm{~cm}^{-1}: 3340(\mathrm{OH}), 3062$ and 3047 (CH, aromatic), 2947 ( $\mathrm{CH}$, aliphatic), $1732(\mathrm{C}=\mathrm{O}), 1647$ $(\mathrm{C}=\mathrm{C}) .{ }^{1} \mathrm{H}$ NMR spectrum, $\delta$, ppm: 0.62-0.60 m $(1 \mathrm{H}, \mathrm{H}-8 \beta)$, $0.91 \mathrm{~s}\left(3 \mathrm{H}, \mathrm{CH}_{3}\right), 1.03-1,00 \mathrm{~m}(1 \mathrm{H}, \mathrm{H}-11 \beta), 1.11-1.08 \mathrm{~m}(1 \mathrm{H}$,

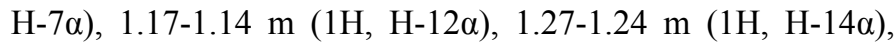

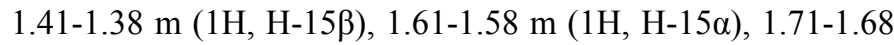
$\mathrm{m}(1 \mathrm{H}, \mathrm{H}-7 \beta), 1.78-1.75 \mathrm{~m}(1 \mathrm{H}, \mathrm{H}-16 \alpha), 2.05-2.02 \mathrm{~m}(1 \mathrm{H}$, $\mathrm{H}-9 \alpha), 2.07-2.04 \mathrm{~m}(1 \mathrm{H}, \mathrm{H}-11 \alpha), 2.32 \mathrm{~s}(1 \mathrm{H}$, pyridyl-CH-

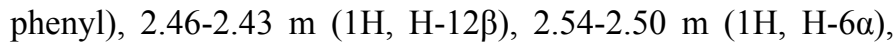

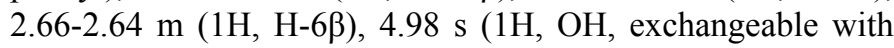
$\left.\mathrm{D}_{2} \mathrm{O}\right), 5.79$ dd $(1 \mathrm{H}, \mathrm{H}-2), 6.69 \mathrm{~d}(1 \mathrm{H}, \mathrm{H}-4), 7.11 \mathrm{~d}(1 \mathrm{H}, \mathrm{H}-1)$, 7.35-7.88 m (9H, Ar-H). ${ }^{13} \mathrm{C}$ NMR spectrum, $\delta$, ppm: 13.81, $21.79,25.87,26.45,29.54,36.55,38.47,43.96,47.50,48.28$, $50.68,58.19,112.80,115.32,124.22,125.88,126.40,126.50$, $132.36,135.90,138.54,147.17,149.62,153.62,164.81$, $218.50(30 \mathrm{C})$. MS (EI): $\mathrm{m} / \mathrm{z} 437(70 \%)\left(\mathrm{M}^{+}\right)$. found, \%: C 82.24; $\mathrm{H}$ 7.10; N 3.15. $\mathrm{C}_{30} \mathrm{H}_{31} \mathrm{NO}_{2}$ (437.57). Calculated, \%: C 82.35 ; H 7.14; N 3.20.

3-hydroxy-16-((aryl)-N-morpholinylmethane)-estra-1 (10), 2, 4-trien-17-one (4a and 4b): A mixture of compounds $2 \mathrm{a}$ and $2 \mathrm{~b}(5 \mathrm{mmol})$ and morpholine $(0.5 \mathrm{ml}, 6 \mathrm{mmol})$ in dioxane $(50 \mathrm{ml})$ was refluxed for $7 \mathrm{~h}$. The reaction mixture was evaporated under reduced pressure to dryness, the obtained residue was dried and crystallized from benzene to give the corresponding products $4 \mathrm{a}$ and $4 \mathrm{~b}$, respectively. 
3-hydroxy-16-((phenyl)-N-morpholinylmethane)-estra-1 (10), 2, 4-trien-17-one (4a): Yield 39\%, m.p. 290-292 ${ }^{\circ} \mathrm{C}$, $(\alpha)^{25}{ }_{\mathrm{D}}=+136(\mathrm{c} 1, \mathrm{MeOH})$. IR spectrum, $v, \mathrm{~cm}^{-1}: 3346(\mathrm{OH})$, 3067 and $3056(\mathrm{CH}$, aromatic), $2950(\mathrm{CH}$, aliphatic), 1733 $(\mathrm{C}=\mathrm{O}), 1648(\mathrm{C}=\mathrm{C}) .{ }^{1} \mathrm{H}$ NMR spectrum, $\delta$, ppm: 0.64-0.62 m $(1 \mathrm{H}, \mathrm{H}-8 \beta), 0.95 \mathrm{~s}\left(3 \mathrm{H}, \mathrm{CH}_{3}\right), 1.04-1.00 \mathrm{~m}(1 \mathrm{H}, \mathrm{H}-11 \beta)$, 1.15-1.13 m (1H, H-7 $\alpha), 1.18-1.17 \mathrm{~m}(1 \mathrm{H}, \mathrm{H}-12 \alpha), 1.27-1.25$ $\mathrm{m}(1 \mathrm{H}, \mathrm{H}-14 \alpha), 1.44-1.40 \mathrm{~m}(1 \mathrm{H}, \mathrm{H}-15 \beta), 1.62-1.60 \mathrm{~m}(1 \mathrm{H}$, $\mathrm{H}-15 \alpha), 1.72-1.70 \mathrm{~m}(1 \mathrm{H}, \mathrm{H}-7 \beta), 1.84-1.82 \mathrm{~m}(1 \mathrm{H}, \mathrm{H}-16 \alpha)$, 2.03-2.00 m (1H, H-9 $\alpha), 2.10-2.08 \mathrm{~m}(1 \mathrm{H}, \mathrm{H}-11 \alpha), 2.46-2.44$ $\mathrm{m}(1 \mathrm{H}, \mathrm{H}-12 \beta), 2.56-2.53 \mathrm{~m}(1 \mathrm{H}, \mathrm{H}-6 \alpha), 2.66-2.64 \mathrm{~m}(1 \mathrm{H}$, $\mathrm{H}-6 \beta), 2.85-2.81 \mathrm{~m}\left(4 \mathrm{H}, 2 \mathrm{CH}_{2}\right), 3.43-3.40 \mathrm{~s}(1 \mathrm{H}, \mathrm{NCH})$, 3.67-3.65 m $\left(4 \mathrm{H}, 2 \mathrm{CH}_{2}\right), 4.97 \mathrm{~s}(1 \mathrm{H}, \mathrm{OH}$, exchangeable with $\left.\mathrm{D}_{2} \mathrm{O}\right), 5.77 \mathrm{dd}(1 \mathrm{H}, \mathrm{H}-2), 6.67 \mathrm{~d}(1 \mathrm{H}, \mathrm{H}-4), 7.10 \mathrm{~d}(1 \mathrm{H}, \mathrm{H}-1)$, 7.28-7.48 (5H, Ar-H). ${ }^{13} \mathrm{C}$ NMR spectrum, $\delta$, ppm: 13.84, 21.66, 25.67, 26.42, 29.34, 36.53, 38.67, 43.94, 46.75, 48.09, $46.75,48.09,50.48,52.85,68.11,112.54,115.78,125.82$, 126.42, 126.56, 132.89, 135.92, 138.44, 153.46, 213.43 (29 C). MS (EI): m/z 445 (100\%) $\left(\mathrm{M}^{+}\right)$. Found, \%: C 78.05; H 7.87; N 3.10. $\mathrm{C}_{29} \mathrm{H}_{35} \mathrm{NO}_{3}$ (445.59). Calculated, \%: C 78.17; H 7.92; N 3.14 .

3-hydroxy-16-((4-pyridyl)-N-morpholinylmethane)-estra-1 (10), 2, 4-trien-17-one (4b): Yield 34\%, m.p. 312-314 ${ }^{\circ} \mathrm{C}$, $(\alpha)^{25} \mathrm{D}^{=+166}(\mathrm{c} 1, \mathrm{MeOH})$. IR spectrum, $v, \mathrm{~cm}^{-1}: 3347(\mathrm{OH})$, 3068 and $3046(\mathrm{CH}$, aromatic), $2945(\mathrm{CH}$, aliphatic), 1742 $(\mathrm{C}=\mathrm{O}), 1643(\mathrm{C}=\mathrm{C}) .{ }^{1} \mathrm{H}$ NMR spectrum, $\delta$, ppm: 0.66-0.64 m $(1 \mathrm{H}, \mathrm{H}-8 \beta), 0.95 \mathrm{~s}\left(3 \mathrm{H}, \mathrm{CH}_{3}\right), 1.05-1.03 \mathrm{~m}(1 \mathrm{H}, \mathrm{H}-11 \beta)$,

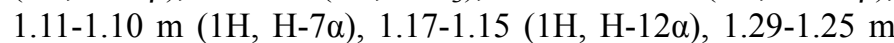
$(1 \mathrm{H}, \mathrm{H}-14 \alpha), 1.44-1.42 \mathrm{~m}(1 \mathrm{H}, \mathrm{H}-15 \beta), 1.66-1.64 \mathrm{~m}(1 \mathrm{H}$, $\mathrm{H}-15 \alpha), 1.77-1.75 \mathrm{~m}(1 \mathrm{H}, \mathrm{H}-7 \beta), 1.85-1.83 \mathrm{~m}(1 \mathrm{H}, \mathrm{H}-16 \alpha)$,

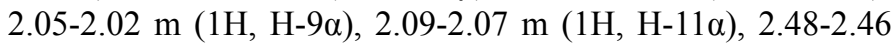
$\mathrm{m}(1 \mathrm{H}, \mathrm{H}-12 \beta), 2.58-2.56 \mathrm{~m}(1 \mathrm{H}, \mathrm{H}-6 \alpha), 2.69-2.67 \mathrm{~m}(1 \mathrm{H}$, $\mathrm{H}-6 \beta), 2.86-2.84 \mathrm{~m}\left(4 \mathrm{H}, 2 \mathrm{CH}_{2}\right), 3.44 \mathrm{~s}(1 \mathrm{H}, \mathrm{NCH}), 3.65-3.63$ $\mathrm{m}\left(4 \mathrm{H}, 2 \mathrm{CH}_{2}\right), 4.96 \mathrm{~s}\left(1 \mathrm{H}, \mathrm{OH}\right.$, exchangeable with $\left.\mathrm{D}_{2} \mathrm{O}\right), 5.80$ dd (1H, H-2), $6.71 \mathrm{~d}(1 \mathrm{H}, \mathrm{H}-4), 7.12 \mathrm{~d}(1 \mathrm{H}, \mathrm{H}-1), 7.33-7.83 \mathrm{~m}$ (4H, Ar-H). ${ }^{13} \mathrm{C}$ NMR spectrum, $\delta$, ppm: 13.88, 21.63, 25.45, 26.89, 29.67, 36.00, 38.45, 43.08, 46.79, 48.25, 50.65, 52.89, $68.22,108.72,112.58,115.68,124.48,126.34,132.54,138.45$, 147.76, 149.55, 153.53, 210.37 (28 C). MS (EI): m/z 446 $(81 \%)\left(\mathrm{M}^{+}\right)$. Found, \%: C 75.22; H 7.60; N 6.20. $\mathrm{C}_{28} \mathrm{H}_{34} \mathrm{~N}_{2} \mathrm{O}_{3}$ (446.58). Calculated, \%: C 75.31; H 7.67; N 6.27.

\section{Synthesis of 5'-(aryl)-estra-1 (10), 2, 4-trien-(17, 16-c) isoxazole-3-ol (5a and 5b)}

A mixture of arylmethylene derivatives $2 \mathrm{a}$ and $2 \mathrm{~b}(5 \mathrm{mmol})$ and hydroxylamine hydrochloride $(6 \mathrm{mmol})$ in sodium ethoxide (46 mg sodium metal in $25 \mathrm{ml}$ absolute ethanol) was refluxed for $7 \mathrm{~h}$. The reaction mixture was evaporated under reduced pressure, the obtained solid was washed with $10 \%$ $\mathrm{HCl}$, filtered off, dried and crystallized from methyl acetate to give isoxazole derivatives $5 \mathrm{a}$ and $5 \mathrm{~b}$, respectively.

5'-(phenyl)-estra-1 (10), 2, 4-trien-(17, 16-c) isoxazole-3-ol (5a): Yield 57\%, m.p. $210-212^{\circ} \mathrm{C},(\alpha)^{25} \mathrm{D}^{=}+145(\mathrm{c} 1, \mathrm{MeOH})$. IR spectrum, $v, \mathrm{~cm}^{-1}: 3347(\mathrm{OH}), 3065$ and $3055(\mathrm{CH}$, aromatic), $2947\left(\mathrm{CH}\right.$, aliphatic), $1614(\mathrm{C}=\mathrm{C}), 1600(\mathrm{C}=\mathrm{N}) .{ }^{1} \mathrm{H}$ NMR spectrum, $\delta$, ppm: 0.65-0.62 m $(1 \mathrm{H}, \mathrm{H}-8 \beta), 0.92 \mathrm{~s}(3 \mathrm{H}$,

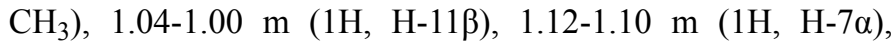

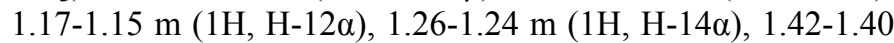
$\mathrm{m}(1 \mathrm{H}, \mathrm{H}-15 \beta), 1.61-1.58 \mathrm{~m}(1 \mathrm{H}, \mathrm{H}-15 \alpha), 1.73-1.70 \mathrm{~m}(1 \mathrm{H}$,

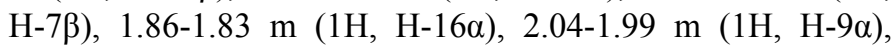
2.11-2.09 m (1H, H-11 $\alpha), 2.45-2.42 \mathrm{~m}(1 \mathrm{H}, \mathrm{H}-12 \beta), 2.56-2.53$ $\mathrm{m}(1 \mathrm{H}, \mathrm{H}-6 \alpha), 2.65-2.61 \mathrm{~m}(1 \mathrm{H}, \mathrm{H}-6 \beta), 4.77 \mathrm{~s}(1 \mathrm{H}$, isoxazole-5'), $4.80 \mathrm{~s}\left(1 \mathrm{H}, \mathrm{OH}\right.$, exchangeable with $\left.\mathrm{D}_{2} \mathrm{O}\right), 5.77$ dd (1H, H-2), $6.68 \mathrm{~d}(1 \mathrm{H}, \mathrm{H}-4), 7.10 \mathrm{~d}(1 \mathrm{H}, \mathrm{H}-1), 7.28-7.41 \mathrm{~m}$ (5H, Ar-H). 13C NMR spectrum, $\delta$, ppm: 13.90, 21.85, 26.21, 26.67, 29.89, 36.78, 38.57, 44.44, 48.69, 50.88, 56.78, 108.46, $112.90,115.65,126.10,126.78,126.80,127.10,136.10$, 133.39, 138.46, 150.67, 153.89 (25 C). MS (EI): m/z 373 $(65 \%)\left(\mathrm{M}^{+}\right)$. Found, \%: C 80.32; $\mathrm{H} 7.20 ; \mathrm{N} 3.70 . \mathrm{C}_{25} \mathrm{H}_{27} \mathrm{NO}_{2}$ (373.48). Calculated, \%: C 80.40; H 7.29; N 3.75.

5'-(4-pyridyl)-estra-1 (10), 2, 4-trien-(17, 16-c) isoxazole-3ol (5b): Yield 47\%, mp $249-251^{\circ} \mathrm{C},(\alpha)^{25} \mathrm{D}=+145(\mathrm{c} 1, \mathrm{MeOH})$. IR spectrum, $v, \mathrm{~cm}^{-1}: 3348(\mathrm{OH}), 3067$ and $3046(\mathrm{CH}$, aromatic), $2945\left(\mathrm{CH}\right.$, aliphatic), $1614(\mathrm{C}=\mathrm{C}), 1608(\mathrm{C}=\mathrm{N}) .{ }^{1} \mathrm{H}$ NMR spectrum, $\delta$, ppm: 0.63-0.60 m $(1 \mathrm{H}, \mathrm{H}-8 \beta), 0.93 \mathrm{~s}(3 \mathrm{H}$, $\left.\mathrm{CH}_{3}\right)$, 1.06-1.04 m (1H, H-11 $\left.\beta\right), 1.14-1.11 \mathrm{~m}(1 \mathrm{H}, \mathrm{H}-7 \alpha)$, 1.15-1.13 m (1H, H-12 $\alpha), 1.27-1.24 \mathrm{~m}(1 \mathrm{H}, \mathrm{H}-14 \alpha), 1.43-1.40$ $\mathrm{m}(1 \mathrm{H}, \mathrm{H}-15 \beta), 1.62-1.60 \mathrm{~m}(1 \mathrm{H}, \mathrm{H}-15 \alpha), 1.74-1.71 \mathrm{~m}(1 \mathrm{H}$,

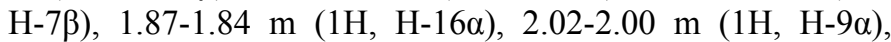
2.08-2.05 m (1H, H-11 $\alpha), 2.48-2.45 \mathrm{~m}(1 \mathrm{H}, \mathrm{H}-12 \beta), 2.56-2.53$ $\mathrm{m}(1 \mathrm{H}, \mathrm{H}-6 \alpha), 2.67-2.65 \mathrm{~m}(1 \mathrm{H}, \mathrm{H}-6 \beta), 4.79 \mathrm{~s}(1 \mathrm{H}$, isoxazole-5'), $4.99 \mathrm{~s}\left(1 \mathrm{H}, \mathrm{OH}\right.$, exchangeable with $\left.\mathrm{D}_{2} \mathrm{O}\right), 5.78$ dd (1H, H-2), $6.67 \mathrm{~d}(1 \mathrm{H}, \mathrm{H}-4), 7.14 \mathrm{~d}(1 \mathrm{H}, \mathrm{H}-1), 7.31-7.81 \mathrm{~m}$ $(4 \mathrm{H}, \mathrm{Ar}-\mathrm{H}) .{ }^{13} \mathrm{C}$ NMR spectrum, $\delta$, ppm: 13.67, 21.65, 25.76, 26.54, 29.76, 36.67, 38.58, 43.67, 48.59, 50.98, 56.89, 108.45, $112.43,115.54,124.45,126.54,132.57,138.43,147.16$, 149.65, 150.69, 153.65 (24 C). MS (EI): m/z $374(91 \%)\left(\mathrm{M}^{+}\right)$. Found, \%: C 76.90; $\mathrm{H} 6.90 ; \mathrm{N} 7.40 . \mathrm{C}_{24} \mathrm{H}_{26} \mathrm{~N}_{2} \mathrm{O}_{2}$ (374.47). Calculated, \%: C 76.98; H 7.00; N 7.48.

\section{Synthesis of (1H)-5'-(aryl)-estra-1 (10), 2, 4-trien-(17, 16-c) pyrazoline-3-ol (6a and 6 b)}

A mixture of $2 \mathrm{a}$ and $2 \mathrm{~d}(4 \mathrm{mmol})$ and hydrazine hydrate (16 mmol) in dioxane $(25 \mathrm{ml})$ was refluxed for $5 \mathrm{~h}$. The solvent was evaporated under reduced pressure, the residue formed was solidified with water, filtered off, washed with water, dried and crystallized from methanol to give the corresponding pyrazoline derivatives $6 \mathrm{a}$ and $6 \mathrm{~b}$, respectively.

(1'H)-5'-(Phenyl)-estra-1(10), 2, 4-trien-(17, 16-c) pyrazoline-3-ol (6a): Yield $66 \%$, mp $278-280^{\circ} \mathrm{C},(\alpha)^{25} \mathrm{D}^{=+137}$ (c1, MeOH). IR spectrum, v, cm ${ }^{-1}: 3347(\mathrm{OH}), 3285(\mathrm{NH})$, 3068 and 3055 ( $\mathrm{CH}$, aromatic), 2947 (CH, aliphatic), 1622 $(\mathrm{C}=\mathrm{C}), 1614(\mathrm{C}=\mathrm{N}) .{ }^{1} \mathrm{H}$ NMR spectrum, $\delta$, ppm: 0.67-0.64 m $(1 \mathrm{H}, \mathrm{H}-8 \beta), 0.93 \mathrm{~s}\left(3 \mathrm{H}, \mathrm{CH}_{3}\right), 1.05-1.03 \mathrm{~m}(1 \mathrm{H}, \mathrm{H}-11 \beta)$, $1.12-1.10$ (1H, H-7 $\alpha), 1.18-1.15 \mathrm{~m}(1 \mathrm{H}, \mathrm{H}-12 \alpha), 1.28-1.15 \mathrm{~m}$ $(1 \mathrm{H}, \mathrm{H}-14 \alpha), 1.45-1.42 \mathrm{~m}(1 \mathrm{H}, \mathrm{H}-15 \beta), 1.61-1.58 \mathrm{~m}(1 \mathrm{H}$, $\mathrm{H}-15 \alpha), 1.73-1.70 \mathrm{~m}(1 \mathrm{H}, \mathrm{H}-7 \beta), 1.86-1.83 \mathrm{~m}(1 \mathrm{H}, \mathrm{H}-16 \alpha)$,

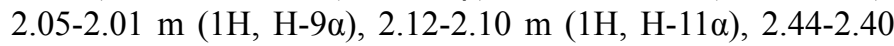
$\mathrm{m}(1 \mathrm{H}, \mathrm{H}-12 \beta), 2.57-2.54 \mathrm{~m}(1 \mathrm{H}, \mathrm{H}-6 \alpha), 2.65-2.61 \mathrm{~m}(1 \mathrm{H}$, $\mathrm{H}-6 \beta), \quad 3.81 \mathrm{~s} \quad(1 \mathrm{H}$, pyrazoline-5 $), 4.80 \mathrm{~s}(1 \mathrm{H}, \mathrm{OH}$, exchangeable with D2O), $5.77 \mathrm{dd}(1 \mathrm{H}, \mathrm{H}-2), 6.68 \mathrm{~d}(1 \mathrm{H}, \mathrm{H}-4)$, $7.10 \mathrm{~d}(1 \mathrm{H}, \mathrm{H}-1), 7.28-7.41 \mathrm{~m}(5 \mathrm{H}, \mathrm{Ar}-\mathrm{H}), 9.85$ bs $(1 \mathrm{H}, \mathrm{NH}$, 
exchangeable with $\left.\mathrm{D}_{2} \mathrm{O}\right) .{ }^{13} \mathrm{C}$ NMR spectrum, $\delta$, ppm: 13.91 , $22.22,26.27,26.88,28.24,30.12,36.90,39.00,44.64,49.00$, 51.09, 64.61, 113.10, 115.77, 126.18, 126.67, 127.11, 127.23, $133.67,136.10,138.86,154.19,163.45$ (25 C). MS (EI): m/z $372(79 \%)\left(\mathrm{M}^{+}\right)$. Found, \%: C 80.70; H 7.52; N 7.45. $\mathrm{C}_{25} \mathrm{H}_{28} \mathrm{~N}_{2} \mathrm{O}$ (372.50). Calculated, \%: C 80.61; H 7.58; N 7.52.

(1'H)-5'-(4-pyridyl)-estra-1(10), 2, 4-trien-(17,16-c) pyrazoline-3-ol (6b): Yield 56\%, mp $250-252^{\circ} \mathrm{C},(\alpha)^{25} \mathrm{D}^{=+140}$ $(\mathrm{c} 1, \mathrm{MeOH})$. IR spectrum, $v, \mathrm{~cm}^{-1}: 3348(\mathrm{OH}), 3288(\mathrm{NH})$, 3068 and 3057 ( $\mathrm{CH}$, aromatic), 2946 (CH, aliphatic), 1624 $(\mathrm{C}=\mathrm{C}), 1616(\mathrm{C}=\mathrm{N}) .{ }^{1} \mathrm{H}$ NMR spectrum, $\delta$, ppm: 0.66-0.64 m $(1 \mathrm{H}, \mathrm{H}-8 \beta), 0.95 \mathrm{~s}\left(3 \mathrm{H}, \mathrm{CH}_{3}\right), 1.03-1.00 \mathrm{~m}(1 \mathrm{H}, \mathrm{H}-11 \beta)$,

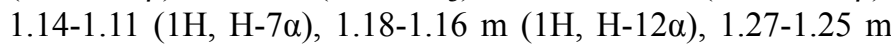
$(1 \mathrm{H}, \mathrm{H}-14 \alpha), 1.44-1.42 \mathrm{~m}(1 \mathrm{H}, \mathrm{H}-15 \beta), 1.62-1.60 \mathrm{~m}(1 \mathrm{H}$, $\mathrm{H}-15 \alpha), 1.75-1.72 \mathrm{~m}(1 \mathrm{H}, \mathrm{H}-7 \beta), 1.89-1.87 \mathrm{~m}(1 \mathrm{H}, \mathrm{H}-16 \alpha)$,

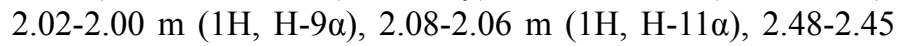
$\mathrm{m}(1 \mathrm{H}, \mathrm{H}-12 \beta), 2.56-2.53 \mathrm{~m}(1 \mathrm{H}, \mathrm{H}-6 \alpha), 2.67-2.65 \mathrm{~m}(1 \mathrm{H}$, $\mathrm{H}-6 \beta), 3.81 \mathrm{~s}(1 \mathrm{H}$, pyrazoline-5 $), 4.91 \mathrm{~s}(1 \mathrm{H}, \mathrm{OH}$, exchangeable with $\left.\mathrm{D}_{2} \mathrm{O}\right), 5.78 \mathrm{dd}(1 \mathrm{H}, \mathrm{H}-2), 6.67 \mathrm{~d}(1 \mathrm{H}, \mathrm{H}-4)$, $7.14 \mathrm{~d}(1 \mathrm{H}, \mathrm{H}-1), 7.34-7.79 \mathrm{~m}(4 \mathrm{H}, \mathrm{Ar}-\mathrm{H}), 9.71$ bs $(1 \mathrm{H}, \mathrm{NH}$, exchangeable with D2O). ${ }^{13} \mathrm{C}$ NMR spectrum, $\delta$, ppm: 13.91 , 21.61, 25.71, 26.54, 28.24, 29.16, 36.17, 38.51, 43.61, 48.51, $50.91,56.89,64.61,112.43,115.54,126.14,124.42,132.51$, 147.13, 149.61, 153.61, 163.45 (24 C). MS (EI): m/z 373 $(91 \%)\left(\mathrm{M}^{+}\right)$. Found, \%: C 77.10; H 7.20; N 11.16. $\mathrm{C}_{24} \mathrm{H}_{27} \mathrm{~N}_{3} \mathrm{O}$ (373.50). Calculated, \%: C 77.18; H 7.29; N 11.25.

\section{Synthesis of 1'-(N-morpholinomethyl)-1H-5'-(aryl)-estra-1 (10), 2, 4-trien-(17, 16-c) pyrazoline-3-ol (7a, and 7b)}

A mixture of $6 \mathrm{a}$ and $6 \mathrm{~b}(1 \mathrm{mmol})$, morpholine $(0.1 \mathrm{~g}, 1 \mathrm{mmol})$ and paraformaldehyde $(0.2 \mathrm{~g})$ in absolute ethanol $(30 \mathrm{ml})$ was refluxed for $2 \mathrm{~h}$. The reaction mixture was evaporated under reduced pressure, the obtained residue was washed with ether, dried, and crystallized from methanol to give $\mathrm{N}$ morpholinopyrazoline derivatives $7 \mathrm{a}$ and $7 \mathrm{~b}$, respectively.

1'-(N-morpholinomethyl)-1H-5'-(phenyl)-estra-1 (10), 2, 4trien-(17, 16-c) pyrazoline-3-ol (7a): Yield 87\%, mp $234-236^{\circ} \mathrm{C},(\alpha)^{25} \mathrm{D}^{=+156}$ (c $\left.1, \mathrm{MeOH}\right)$. IR spectrum, $v, \mathrm{~cm}^{-1}$ : $3340(\mathrm{OH}), 3068$ and $3059(\mathrm{CH}$, aromatic), $2956(\mathrm{CH}$, aliphatic), $1628(\mathrm{C}=\mathrm{C}), 1617(\mathrm{C}=\mathrm{N}) .{ }^{1} \mathrm{H}$ NMR spectrum, $\delta$,

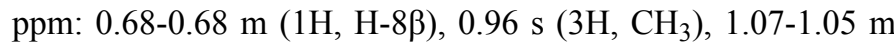
$(1 \mathrm{H}, \mathrm{H}-11 \beta), 1.14-1.12 \mathrm{~m}(1 \mathrm{H}, \mathrm{H}-7 \alpha), 1.18-1.15 \mathrm{~m}(1 \mathrm{H}$,

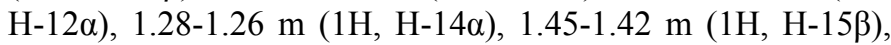

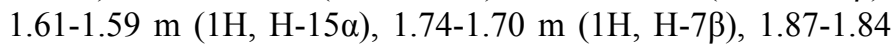
$\mathrm{m}(1 \mathrm{H}, \mathrm{H}-16 \alpha), 2.06-2.02 \mathrm{~m}(1 \mathrm{H}, \mathrm{H}-9 \alpha), 2.14-2.10 \mathrm{~m}(1 \mathrm{H}$, $\mathrm{H}-11 \alpha), 2.34 \mathrm{~s}\left(2 \mathrm{H}, \mathrm{NCH}_{2} \mathrm{~N}\right), 2.47-2.45 \mathrm{~m}(1 \mathrm{H}, \mathrm{H}-12 \beta)$, 2.59-2.56 m (1H, H-6 $\alpha), 2.66-2.64 \mathrm{~m}(1 \mathrm{H}, \mathrm{H}-6 \beta), 2.85-2.82 \mathrm{~m}$ $\left(4 \mathrm{H}, 2 \mathrm{CH}_{2}\right), \quad 3.67-3.65 \mathrm{~m}\left(4 \mathrm{H}, 2 \mathrm{CH}_{2}\right), 3.86 \mathrm{~s} \quad(1 \mathrm{H}$, pyrazoline-5 $), 4.87 \mathrm{~s}\left(1 \mathrm{H}, \mathrm{OH}\right.$, exchangeable with $\left.\mathrm{D}_{2} \mathrm{O}\right), 5.78$ dd (1H, H-2), $6.69 \mathrm{~d}(1 \mathrm{H}, \mathrm{H}-4), 7.10 \mathrm{~d}(1 \mathrm{H}, \mathrm{H}-1), 7.27-7.47 \mathrm{~m}$ (5H, Ar-H). ${ }^{13} \mathrm{C}$ NMR spectrum, $\delta$, ppm: 13.65, 22.57, 26.37, 26.85, 27.34, 28.89, 30.67, 36.93, 39.56, 44.34, 46.56, 49.67, $51.19,64.32,66.58,68.17,113.15,115.37,126.10,126.60$, 127.56, 133.37, 136.34, 138.84, 154.49, 163.57 (30 C). MS (EI): $\mathrm{m} / \mathrm{z} 471(59 \%)\left(\mathrm{M}^{+}\right)$. Found, \%: C 76.28; H 7.82; N 8.84. $\mathrm{C}_{30} \mathrm{H}_{37} \mathrm{~N}_{3} \mathrm{O}_{2}$ (471.63). Calculated, \%: C 76.40; H 7.91; N 8.91.
1'-(N-morpholinomethyl)-1H-5'-(4-pyridyl)-estra-1 (10), 2, 4-trien-(17, 16-c) pyrazoline-3-ol (7b): Yield 77\%, mp $288-290^{\circ} \mathrm{C},(\alpha)^{25} \mathrm{D}^{=+131}(\mathrm{c} 1, \mathrm{MeOH})$. IR spectrum, $v, \mathrm{~cm}^{-1}$ : $3348(\mathrm{OH}), 3077$ and $3050(\mathrm{CH}$, aromatic), $2949(\mathrm{CH}$, aliphatic), $1628(\mathrm{C}=\mathrm{C}), 1617(\mathrm{C}=\mathrm{N}) .{ }^{1} \mathrm{H}$ NMR spectrum, $\delta$,

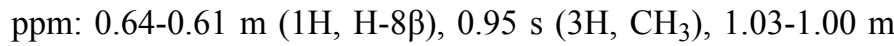
$(1 \mathrm{H}, \mathrm{H}-11 \beta), 1.14-1.12 \mathrm{~m}(1 \mathrm{H}, \mathrm{H}-7 \alpha), 1.18-1.16 \mathrm{~m}(1 \mathrm{H}$, H-12 $\alpha), 1.27-1.24 \mathrm{~m}(1 \mathrm{H}, \mathrm{H}-14 \alpha), 1.44-1.41 \mathrm{~m}(1 \mathrm{H}, \mathrm{H}-15 \beta)$,

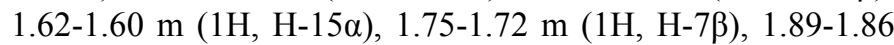
$\mathrm{m}(1 \mathrm{H}, \mathrm{H}-16 \alpha), 2.02-1.99 \mathrm{~m}(1 \mathrm{H}, \mathrm{H}-9 \alpha), 2.08-2.05 \mathrm{~m}(1 \mathrm{H}$, $\mathrm{H}-11 \alpha), 2.34 \mathrm{~s}\left(2 \mathrm{H}, \mathrm{NCH}_{2} \mathrm{~N}\right), 2.48-2.45 \mathrm{~m}(1 \mathrm{H}, \mathrm{H}-12 \beta)$,

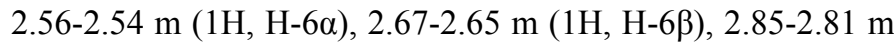
$\left(4 \mathrm{H}, \mathrm{CH}_{2}\right), \quad 3.67-3.65 \mathrm{~m}\left(4 \mathrm{H}, 2 \mathrm{CH}_{2}\right), 3.81 \mathrm{~s}(1 \mathrm{H}$, pyrazoline-5 $), 4.91 \mathrm{~s}\left(1 \mathrm{H}, \mathrm{OH}\right.$, exchangeable with $\left.\mathrm{D}_{2} \mathrm{O}\right), 5.78$ dd (1H, H-2), $6.67 \mathrm{~d}(1 \mathrm{H}, \mathrm{H}-4), 7.14 \mathrm{~d}(1 \mathrm{H}, \mathrm{H}-1), 7.34-7.79 \mathrm{~m}$ (4H, Ar-H). ${ }^{13} \mathrm{C}$ NMR spectrum, $\delta$, ppm: 13.90, 21.78, 25.67, 26.54, 28.54, 29.56, 36.46, 38.65, 43.67, 46.90, 48.43, 50.35, $56.67,64.45,66.89,68.80,112.57,115.68,124.62,126.17$, $138.69,147.17,149.69,153.37,163.58$ (29 C). MS (EI): m/z $472(100 \%)\left(\mathrm{M}^{+}\right)$. Found, \%: C 73.58; H 7.60; N 11.78. $\mathrm{C}_{29} \mathrm{H}_{36} \mathrm{~N}_{4} \mathrm{O}_{2}$ (472.60). Calculated, \%: C 73.70; H 7.68; N 11.85 .

\section{Synthesis of 1'-(N-thiophenol methano)-1H-5'-(aryl)- estra-1 (10), 2, 4-trien (17, 16-c) pyrazoline-3-ol (8a and $8 b)$}

A mixture of $5 \mathrm{a}$ and $5 \mathrm{~b}(1 \mathrm{mmol})$, thiophene $(0.1 \mathrm{~g}, 1 \mathrm{mmol})$, and paraformaldehyde $(0.2 \mathrm{~g})$ in absolute ethanol $(30 \mathrm{ml})$ was refluxed for $2 \mathrm{~h}$. The reaction mixture was evaporated under reduced pressure, dried, and crystallized to give $7 \mathrm{a}$ and $7 \mathrm{~b}$, respectively.

1'-(N-thiophenol methano)-1H-5'-(phenyl)-estra-1 (10), 2, 4-trien-(17, 16-c0 pyrazoline-3-ol (8a): Yield 81\%, mp $270-272^{\circ} \mathrm{C},(\alpha)^{25} \mathrm{D}^{=+105}(\mathrm{c} 1, \mathrm{MeOH})$. IR spectrum, $v, \mathrm{~cm}^{-1}$ : $3346(\mathrm{OH}), 3077$ and $3067(\mathrm{CH}$, aromatic), $2957(\mathrm{CH}$, aliphatic), $1627(\mathrm{C}=\mathrm{C}), 1618(\mathrm{C}=\mathrm{N}) .{ }^{1} \mathrm{H}$ NMR spectrum, $\delta$,

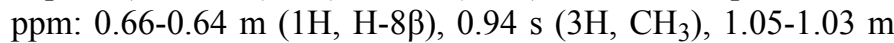
$(1 \mathrm{H}, \mathrm{H}-11 \beta), 1.15-1.12 \mathrm{~m}(1 \mathrm{H}, \mathrm{H}-7 \alpha), 1.20-1.18 \mathrm{~m}(1 \mathrm{H}$, H-12 $\alpha), 1.30-1.28 \mathrm{~m}(1 \mathrm{H}, \mathrm{H}-14 \alpha), 1.47-1.45 \mathrm{~m}(1 \mathrm{H}, \mathrm{H}-15 \beta)$,

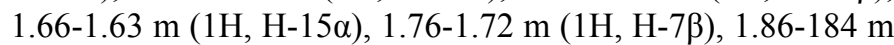
$(1 \mathrm{H}, \mathrm{H}-16 \alpha), 2.11-2.09 \mathrm{~m}(1 \mathrm{H}, \mathrm{H}-9 \alpha), 2.17-2.14 \mathrm{~m}(1 \mathrm{H}$,

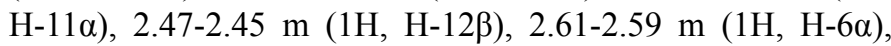
2.68-2.64 m (1H, H-6 3$), 3.88 \mathrm{~s}(1 \mathrm{H}$, pyrazoline-5'), $3.88 \mathrm{~s}(2 \mathrm{H}$, $\mathrm{NCH} 2 \mathrm{~S}), 4.88 \mathrm{~s}\left(1 \mathrm{H}, \mathrm{OH}\right.$, exchangeable with $\left.\mathrm{D}_{2} \mathrm{O}\right), 5.79 \mathrm{dd}$ (1H, H-2), $6.68 \mathrm{~d}(1 \mathrm{H}, \mathrm{H}-4), 7.11 \mathrm{~d}(1 \mathrm{H}, \mathrm{H}-1), 7.27-7.88 \mathrm{~m}$ (10H, Ar-H). ${ }^{13} \mathrm{C}$ NMR spectrum, $\delta$, ppm: 13.75, 22.58, 26.56, 26.78, 28.89, 30.67, 36.93, 39.56, 44.79, 49.11, 49.70, 51.68, $64.37,113.45,115.37,125.05,126.10,126.60,126.67,127.45$, $127.56,128.82,133.37,135.12,136.14,138.69,154.67$, 163.58 (32 C). MS (EI): m/z $494(100 \%)\left(\mathrm{M}^{+}\right)$. Found, \%: C 77.60; $\mathrm{H}$ 6.86; $\mathrm{N}$ 5.60; $\mathrm{S}$ 6.40. $\mathrm{C}_{32} \mathrm{H}_{34} \mathrm{~N}_{2} \mathrm{OS}$ (494.67). Calculated, \%: C 77.69; H 6.93; N 5.66; S 6.48.

1'-(N-thiophenol methanol)-1H-5'-(4-pyridyl)-estra-1 (10), 2, 4-trien (17, 16-c) pyrazoline-3-ol (8b): Yield 80\%, mp $222-224^{\circ} \mathrm{C},(\alpha)^{25} \mathrm{D}^{=+100}(\mathrm{c} 1, \mathrm{MeOH})$. IR spectrum, $v, \mathrm{~cm}^{-1}$ : $3340(\mathrm{OH}), 3070$ and $3050(\mathrm{CH}$, aromatic), $2940(\mathrm{CH}$, 
aliphatic), $1620(\mathrm{C}=\mathrm{C}), 1610(\mathrm{C}=\mathrm{N}) .1 \mathrm{H}$ NMR spectrum, $\delta$, ppm: $0.65-0.63 \mathrm{~m}(1 \mathrm{H}, \mathrm{H}-8 \beta), 0.94 \mathrm{~s}\left(3 \mathrm{H}, \mathrm{CH}_{3}\right), 1.03-1.00 \mathrm{~m}$ $(1 \mathrm{H}, \mathrm{H}-11 \beta), 1.16-1.13 \mathrm{~m}(1 \mathrm{H}, \mathrm{H}-7 \alpha), 1.17-1.14 \mathrm{~m}(1 \mathrm{H}$,

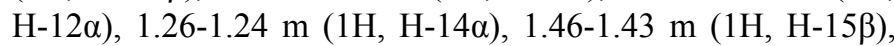

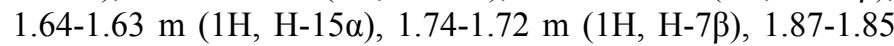
$\mathrm{m}(1 \mathrm{H}, \mathrm{H}-16 \alpha), 2.00-1.98 \mathrm{~m}(1 \mathrm{H}, \mathrm{H}-9 \alpha), 2.07-2.05 \mathrm{~m}(1 \mathrm{H}$, $\mathrm{H}-11 \alpha), 2.49-2.46 \mathrm{~m}(1 \mathrm{H}, \mathrm{H}-12 \beta), 2.58-2.56 \mathrm{~m}(1 \mathrm{H}, \mathrm{H}-6 \alpha)$, 2.68-2.65 m (1H, H-6ß), $3.80 \mathrm{~s}(1 \mathrm{H}$, pyrazoline-5'), $3.88 \mathrm{~s}(2 \mathrm{H}$, $\left.\mathrm{NCH}_{2} \mathrm{~S}\right), 4.92 \mathrm{~s}(1 \mathrm{H}, \mathrm{OH}$, exchangeable with D2O), $5.76 \mathrm{dd}$ $(1 \mathrm{H}, \mathrm{H}-2), 6.68 \mathrm{~d}(1 \mathrm{H}, \mathrm{H}-4), 7.12 \mathrm{~d}(1 \mathrm{H}, \mathrm{H}-1), 7.34-7.90 \mathrm{~m}$ $(9 \mathrm{H}, \mathrm{Ar}-\mathrm{H}) .{ }^{13} \mathrm{C}$ NMR spectrum, $\delta$, ppm: 13.95, 21.72, 25.60, 26.50, 28.53, 29.50, 36.40, 38.60, 43.60, 48.40, 49.11, 50.31, $56.67,64.46,112.57,115.68,124.69,125.05,126.67,128.82$, 132.90, 135.12, 138.69, 147.10, 149.67, 153.78, 163.54 (31 C). MS (EI): m/z 495 (100\%) (M+). Found, \%: C 75.02; H 6.62; N 8.40; S 6.40. $\mathrm{C}_{31} \mathrm{H}_{33} \mathrm{~N}_{3} \mathrm{OS}$ (495.67). Calculated, \%: C, 75.12; $\mathrm{H}, 6.71 ; \mathrm{N}, 8.48 ; \mathrm{S}, 6.47$.

\section{Pharmacological screening}

In vitro $(3 \mathrm{H})$ thymidine uptake in cultured mouse ovaries: Using the adopted method [22].

Ovarian weight in HCG-primed rats: Using the adopted method [22]: Receptor binding assay for FSH: Membrane preparations from bovine testes are used according to the methods of Cheng [23] and Andersen [24], and follow up the adopted method [22].

Measurement of drug levels in plasma and in different organ samples: Drug levels in plasma and in different organ samples were measured by liquid chromatography as previously described [25]. And follow up the adopted method [26].

\section{Results and Discussion}

\section{Chemistry}

The arylidene derivatives were prepared and subjected to both Grignard addition using phenyl magnesium bromide and 1, 4 Micheal addition using morpholine. Also the isoxazole and the pyrazoline derivative confined to ring $\mathrm{D}$ of estrone were prepared from these arylidene. The pyrozoline derivatives were converted to their Mannich derivatives using morpholine and thiophene. All the synthesized compounds were screened as follicle-stimulating hormone (FSH) agents. Follicle-stimulating hormone increases dose-dependent the amount of $\left({ }^{3} \mathrm{H}\right)$ thymidine uptake by cultured mouse ovaries. In vivo method the relative potency to standard reference drug pergonal was calculated. Receptor binding assay for FSH calculate the specific binding percentage of each of the tested compounds to its Receptor. Also, in vivo pharmacokinetic and pharmacodynamic profiles of the some newly synthesized agents were evaluated in at the end of experiment in (PM).

Treating of estrone (3-hydroxyestran-17-one, 1) with benzaldehyde and 4-pyridinecarbaldehyde afforded the corresponding arylidene derivatives $2 \mathrm{a}$ and $2 \mathrm{~b}$, respectively, which were treated with Grignard reagent (phenyl magnesium bromide) to afford the corresponding 1, 4 addition products $3 \mathrm{a}$ and $3 \mathrm{~b}$, respectively. Also, arylidene derivatives $2 \mathrm{a}$ and $2 \mathrm{~b}$ were reacted with hydroxyl amine hydrochloride or morpholine to afford the corresponding 1, 4 Michael addition products $4 \mathrm{a}$ and $4 \mathrm{~b}$, and isoxazoles $5 \mathrm{a}$ and $5 \mathrm{~b}$, respectively (Scheme 1).

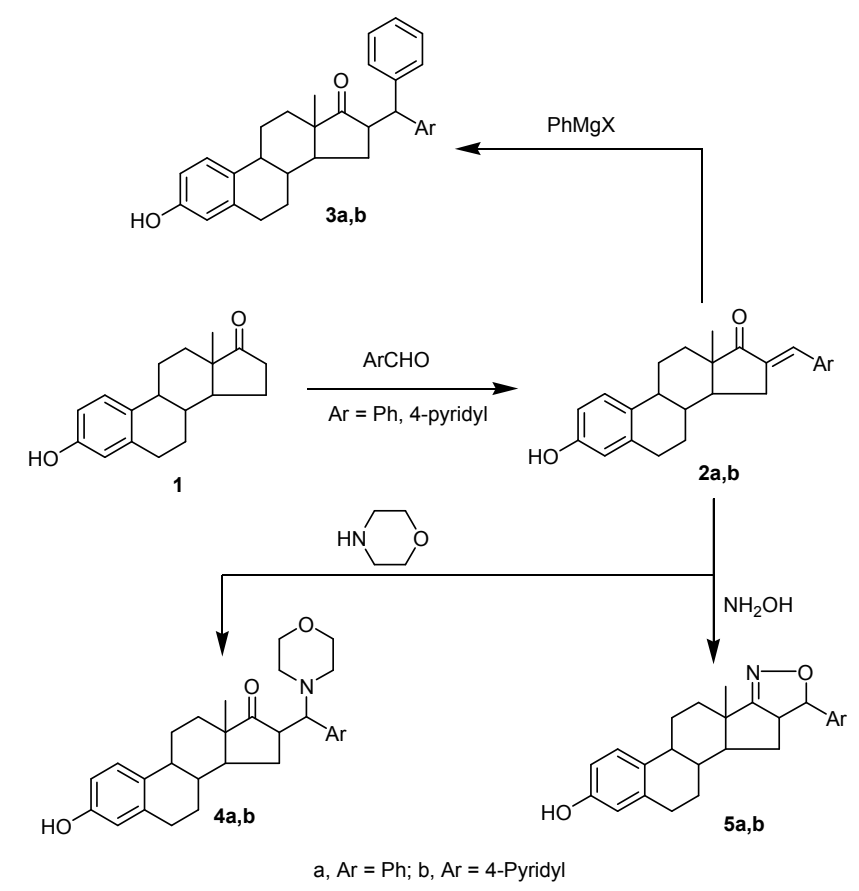

Scheme 1. Synthetic routes to starting compounds 2-5.

Condensation of $2 \mathrm{a}$ and $2 \mathrm{~b}$ with hydrazine hydrate afforded the corresponding pyrazoline derivatives $6 \mathrm{a}$ and $6 \mathrm{~b}$, respectively. The latter compounds $6 \mathrm{a}$ and $6 \mathrm{~b}$ were treated with morpholine and paraformaldehyde under the Mannich reaction afforded the corresponding Mannich reaction products $7 \mathrm{a}$ and $7 \mathrm{~b}$, respectively. Finally, treating of $6 \mathrm{a}$ and $6 \mathrm{~b}$ with thiophenol and paraformaldehyde under the Mannich reaction afforded the corresponding Mannich reaction products $8 \mathrm{a}$ and $8 \mathrm{~b}$, respectively (Scheme 2).

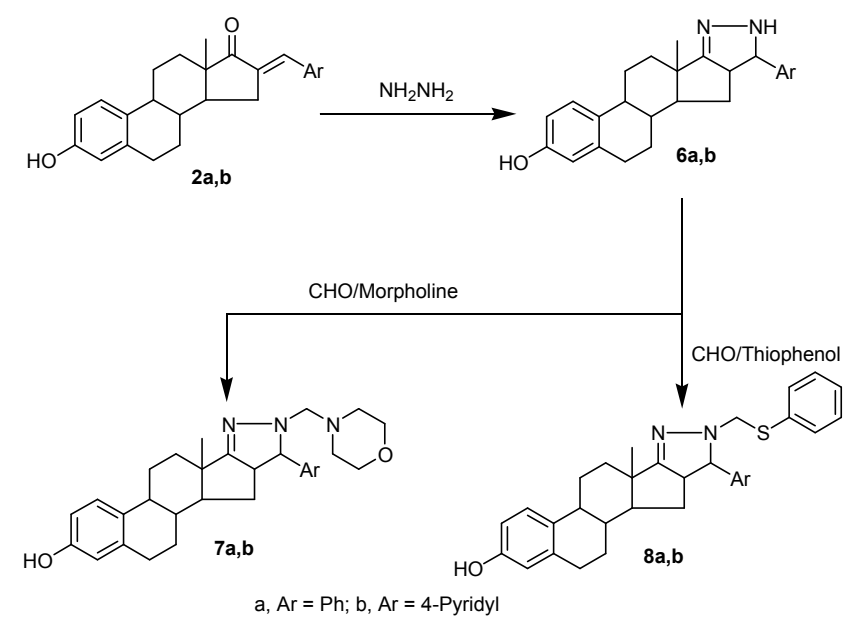

Scheme 2. Synthetic routes to starting compounds 6-8. 


\section{Pharmacological screening}

In vitro $\left({ }^{3} \mathrm{H}\right)$ thymidine uptake in cultured mouse ovaries [27,28]: Follicle-stimulating hormone increases dosedependent the amount of $\left({ }^{3} \mathrm{H}\right)$ thymidine uptake by cultured mouse ovaries. This in vitro bioassay for FSH uses a tissue specific proliferation response. In this in vitro preliminary screening method, the $\mathrm{IC}_{90}(\mu \mathrm{M})$ or the doses of the tested compounds that cause $90 \%$ increases in the amount of $\left({ }^{3} \mathrm{H}\right)$ thymidine uptake by cultured mouse ovaries were calculated and tabulated in Table 1.

Table 1. IC 90 ( $\mu M)$ of the tested compounds for in vitro $\left({ }^{3} \mathrm{H}\right)$ thymidine uptake in cultured mouse ovaries model.

\begin{tabular}{ll}
\hline Comp. no. & IC $_{90}(\mathbf{n M})$ \\
\hline $2 \mathrm{a}$ & 7.58 \\
\hline $2 \mathrm{~b}$ & 7.04 \\
\hline $3 \mathrm{a}$ & 6.91 \\
\hline $3 \mathrm{~b}$ & 6.55 \\
\hline $4 \mathrm{a}$ & 6.22 \\
\hline $4 \mathrm{~b}$ & 6.12 \\
\hline $5 \mathrm{a}$ & 5.91 \\
\hline $5 \mathrm{~b}$ & 5.88 \\
\hline $6 \mathrm{a}$ & 5.77 \\
\hline $6 \mathrm{~b}$ & 5.26 \\
\hline $7 \mathrm{a}$ & 4.56 \\
\hline $7 \mathrm{~b}$ & 4.11 \\
\hline $8 \mathrm{a}$ & 3.78 \\
\hline $8 \mathrm{~b}$ & 3.44 \\
\hline Pergonal & 22.8 \\
\hline & $5.6 . M$ \\
\hline
\end{tabular}

Values are standard error of mean ( \pm S.E.M), $n=6$ in each group; Statistical analysis by one way Analysis of Variance (ANOVA) followed by Dunnet test using Graphpad Instat software $(\mathrm{P}<0.05)$.

Ovarian weight in HCG-primed rats: Follicle-stimulating hormone (FSH) increases the weight of ovaries in immature rats by inducing follicular maturation [29]. This effect is greatly enhanced by simultaneous administration of a constant dose of human chorionic gonadotropin (HCG) for additional luteinization allowing the detection of low amounts of FSH. In this in vivo method the relative potency to standard reference drug pergonal were calculated and given in Table 2 .

Table 2. Relative potency of the tested compounds in ovarian weight in HCG-primed rats model.

\begin{tabular}{ll}
\hline Comp. no. & Relative potency \\
\hline $2 \mathrm{a}$ & 2.33 \\
\hline $2 \mathrm{~b}$ & 2.55 \\
\hline $3 \mathrm{a}$ & 2.99 \\
\hline
\end{tabular}

\begin{tabular}{ll}
\hline $3 b$ & 3.12 \\
\hline $4 a$ & 3.56 \\
\hline $4 b$ & 3.78 \\
\hline $5 a$ & 4.67 \\
\hline $5 b$ & 4.78 \\
\hline $6 a$ & 4.97 \\
\hline $6 b$ & 5.12 \\
\hline $7 a$ & 5.34 \\
\hline $7 b$ & 5.35 \\
\hline $8 a$ & 5.50 \\
\hline $8 b$ & 5.66 \\
\hline Pergonal
\end{tabular}

Values are standard error of mean ( \pm S.E.M), $n=6$ in each group; Statistical analysis by one way Analysis of Variance (ANOVA) followed by Dunnet test using Graphpad Instat software $(P<0.05)$.

Values are standard error of mean $( \pm$ S.E.M), $n=6$ in each group; Statistical analysis by one way Analysis of Variance (ANOVA) followed by Dunnet test using Graphpad Instat software $(\mathrm{P}<0.05)$.

Receptor binding assay for FSH: Significant differences between biological activity and receptor binding activity of FSH preparations have been found by Marana et al. [30], Zaid et al. [31], Foulds et al. [26], and Burgon et al. [32]. This is attributed to the assay principle of measuring binding activity, but not subsequent intracellular signaling. Several receptors binding assay procedures have been described, e.g. Cheng [23], Andersen [24] using bovine testes and Reichert [22,25] was using rat testes tubule tissue. So this method calculate the specific binding percentage of each of the tested compounds to its receptor and given in Table 3.

Table 3. Specific binding of the tested compounds for receptor binding assay for FSH model.

\begin{tabular}{ll}
\hline Comp. no. & Specific binding (\%) \\
\hline $2 a$ & 79.11 \\
\hline $2 b$ & 80.19 \\
\hline $3 a$ & 81.56 \\
\hline $3 b$ & 82.67 \\
\hline $4 a$ & 83.00 \\
\hline $4 b$ & 83.56 \\
\hline $5 a$ & 84.23 \\
\hline $5 b$ & 84.45 \\
\hline $6 a$ & 85.23 \\
\hline $6 b$ & 85.60 \\
\hline $7 a$ & 86.00 \\
\hline
\end{tabular}




\begin{tabular}{ll}
\hline $7 \mathrm{~b}$ & 86.78 \\
\hline $8 \mathrm{a}$ & 87.67 \\
\hline $8 \mathrm{~b}$ & 88.88 \\
\hline Pergonal $^{\circledR}$ & 58.88 \\
\hline
\end{tabular}

Values are standard error of mean $( \pm$ S.E.M), $n=6$ in each group; Statistical analysis by one way Analysis of Variance (ANOVA) followed by Dunnet test using Graphpad Instat software $(P<0.05)$.

Pharmacokinetics and pharmacodynamics profiles of the tested agents: Ovarian drug conc. in female Sprague-Dawley rats (ovarian weight in $\mathrm{HCG}$-primed rats) $\mathrm{nM}$ and plasma drug conc. in female Sprague-Dawley rats (ovarian weight in HCGprimed rats) $\mathrm{nM}$ were measured and given in Table 4 indicating good pharmacokinetics and pharmacodynamics properties of the tested agents.

Table 4. In vivo pharmacokinetic and pharmacodynamic profiles of the some newly synthesized agents were evaluated in at the end of experiment in $(P M)$.

\begin{tabular}{|c|c|c|}
\hline Comp. no. & $\begin{array}{l}\text { Ovarian drug conc. in female } \\
\text { Sprague-Dawley r rats } \\
\text { (ovarian weight in HCG- } \\
\text { primed rats) PM }\end{array}$ & $\begin{array}{l}\text { Plasma drug conc. in female } \\
\text { Sprague-Dawley r rats } \\
\text { (ovarian weight in HCG- } \\
\text { primed rats) PM }\end{array}$ \\
\hline $2 a$ & 4.56 & 5.67 \\
\hline $2 b$ & 5.12 & 6.32 \\
\hline $3 a$ & 5.66 & 6.56 \\
\hline $3 b$ & 5.78 & 7.12 \\
\hline $4 a$ & 5.99 & 7.67 \\
\hline $4 b$ & 6.10 & 8.14 \\
\hline $5 a$ & 6.35 & 8.46 \\
\hline $5 b$ & 6.79 & 8.78 \\
\hline $6 a$ & 7.13 & 9.00 \\
\hline $6 b$ & 7.45 & 9.13 \\
\hline $7 a$ & 7.68 & 9.34 \\
\hline $7 b$ & 7.88 & 9.99 \\
\hline $8 a$ & 7.91 & 10.22 \\
\hline $8 b$ & 8.90 & 11.14 \\
\hline Pergonal ${ }^{\circledR}$ & 3.33 & 4.35 \\
\hline \multicolumn{3}{|c|}{$\begin{array}{l}\text { Values are standard error of mean }( \pm \text { S.E.M), } n=6 \text { in each group; Statistical } \\
\text { analysis by one way Analysis of Variance (ANOVA) followed by Dunnet test } \\
\text { using Graphpad Instat software }(P<0.05)\end{array}$} \\
\hline
\end{tabular}

\section{Structure activity relationship (SAR)}

- 16-arylidene or benzylidene increases the activity, where adding more electronegative nitrogen atom increases the FSH activities.

- Building 5 member ring system increases the activity, where pyrazoline provide more FSH activities than isoxazole.
- The substitution on the NH of pyrazoline increases the FSH activities.

- Sulfur atom increases the activity more than its $\mathrm{CH}_{2}$ bioisoster.

\section{Conclusion}

In our study was to synthesize and screened as folliclestimulating hormone (FSH) agents of novel series of arylidiene, isoxazole, pyrazolines, and their derivatives 2-8 from estrone (3-hydroxyestran-17-one, 1) as starting material. The arylidene derivatives were prepared and subjected to both Grignard addition using phenyl magnesium bromide and 1, 4 Micheal addition using morpholine. Also the isoxazole and the pyrazoline derivative confined to ring $\mathrm{D}$ of estrone were prepared from these arylidene. The pyrozoline derivatives were converted to their Mannich derivatives by using morpholine and thiophene. All the synthesized compounds were screened as follicle-stimulating hormone (FSH) agents.

\section{Acknowledgment}

The authors acknowledge the President of Taibah University, Al-Madina AL-Munawara, Kingdom of Saudi Arabia to provide ongoing support for scientific research. Also, the authors extend their appreciation to the Deanship of Scientific Research and Toxicological Research Center in Taibah University, Al-Madina AL-Munawara, Kingdom of Saudi Arabia for funding this work through the research group project NO. 8014/1437.

\section{References}

1. Nyffenegger C, Fournet G, Joseph B. Synthesis of 3amino-5H-pyrrolo (2, 3-e)-1, 2, 4-triazines by sonogashira/copper(I)-catalyzed heteroannulation. Tetrahedron Lett 2007; 48: 5069-5072.

2. Sztanke K, Fidecka S, Kedzierska E, Karczmarzyk Z, Pihlaja K, Matosiuk D. Antinociceptive activity of new imidazolidine carbonyl derivatives. part 4. synthesis and pharmacological activity of 8-aryl-3, 4-dioxo-2h, 8h-6, 7dihydroimidazo(2, 1-c)(1, 2, 4) triazines. Eurp J Med Chem 2005; 40: 127-134.

3. Holla BS, Gonsalves R, Rao BS, Shenoy S, Gopalakrishna HN. Synthesis of some new biologically active bis-(thiadiazolotriazines) and bis(thiadiazolotriazinyl) alkanes. Farmaco 2001; 56: 899-903.

4. Kumar R, Sirohi TS, Singh H, Yadav R, Roy RK, Chaudhary A, Pandeya SN1. 1, 2, 4-triazine analogs as novel class of therapeutic agents. Mini Rev Med Chem 2014; 14: 168-207.

5. Mullick P, Khan SA, Begum T, Verma S, Kaushik D, Alam O. Synthesis of 1, 2, 4-triazine derivatives as potential anti-anxiety and anti-inflammatory agents. Acta Pol Pharm 2009; 66: 379-385.

6. Singh S, Husain K, Athar F, Azam A. Synthesis and antiamoebic activity of 3, 7-dimethyl-pyrazolo(3, 4-e)(1, 
2, 4)triazin-4-yl-thiosemicarbazide derivatives. Eur J Pharm Sci 2005; 25: 255-262.

7. Bishnoi A, Singh S, Tiwari AK, Rani A, Jain S, Tripathi CKM. Synthesis and antimicrobial activity of some new 1, 2, 4-triazine and benzimidazole derivatives. Ind J Chem 2014; 53: 325-331.

8. Fayed AA, El-Farargy AF, Yousif NM, Gad FA, Kalmouch AA. Synthesis, anti-microbial evaluation and cytotoxicity bioassay of some synthesized novel pyridazine derivatives comparison to standard drugs. Der Pharma Chem 2015; 7: 316-322.

9. Paul R, Brockman JA, Hallett WA, Hanifin JW, Tarrant ME, Torley LW, Callahan FM, Fabio PF, Johnson BD, Lenhard RH. Imidazo(1, 5-d)(1, 2, 4)triazines as potential antiasthma agents. J Med Chem 1985; 28: 1704-1716.

10. Mohamed SF, Ibrahiem AA, Amr AE, Abdalla MM. SARS-CoV 3C-Like protease inhibitors of some newly synthesized substituted pyrazoles and substituted pyrimidines based on 1-(3-aminophenyl)-3-(1h-indol-3yl)prop-2-en-1-one. Int J Pharmacol 2015; 11: 749-756.

11. Farag AM, Mayhoub AS, Eldebss TMA, Amr AE, Ali KK, Abdel-Hafez NA, Abdulla MM. Synthesis and structure-activity relationship studies of pyrazole-based heterocycles as antitumor agents. Arch Pharm Chem Life Sci 2010; 343: 384-396.

12. Farag AM, Ali KAK, El-Debss TMA, Mayhoub AS, Amr AE, Abdel-Hafez NA, Abdulla MM. Design, synthesis and structure-activity relationship study of novel pyrazole-based heterocycles as potential antitumor agents. Eur J Med Chem 2010; 45: 5887-5898.

13. Bahashwan SA, Fayed AA, Ramadan MA, Amr AE, AlHarbi NO. Androgen receptor antagonists and antiprostate canceractivities of some newly synthesized substituted fused pyrazolo-, triazolo- and thiazolopyrimidine derivatives. Int $\mathrm{J}$ Mol Sci 2014; 15: 21587-21602.

14. Amr AE, Abdalla MM, Essaouy SA, Areef MH, Nassear TA, Haschich AE. Synthesis of some substituted furo(3, 2-g)chromeno(2, 3-c)pyrazole and pyrazoline derivatives from 5-hydroxybergapten and 5-hydroxyisopimpinellin as EGFR and VEGFR-2 kinase inhibitors. Rus J Gen Chem 2017; 87: 1601-1609.

15. Said SA, El-Sayed HA, El-Farargy AF, Amr AE, Ibrahim S, Abdalla MM. Pharmacological activities of some synthesized substituted pyrazole, oxazole and triazolopyrimidine derivatives. Lat Am J Pharm 2016; 35: 1618-1625.

16. Amr AE, Abdel-Latif NA, Abdalla M M. Synthesis of some new testosterone derivatives fused with substituted pyrazoline ring as promising 5a-reductase inhibitors. Acta Pharmaceutica 2006; 56: 203-218.

17. Abdulla MM, Amr AE, Al-Omar MA, Hussain AA, Amer MS. Synthesis and reactions of some new substituted androstanopyrazoline and androstanoisoxazole derivatives using their arylmethylene as starting materials. Life Sci J 2013; 4: 599-607.
18. Ouf NH, Amr AE. Synthesis and antiinflammatory activity of some pyrimidines and thienopyrimidines using 1-(2-benzo(d)(1, 3)dioxol-5-yl)vinyl)-4-mercapto-6methyl pyrimidine-5-yl)ethan-2-one as a starting material. Monatshefte fur Chemie 2008; 139: 579-585.

19. Amr AE, Abdulla MM. Synthesis and anti-inflammatory activities of new cyanopyrane derivatives fused with steroidal nuclei. Archiv der Pharmazie 2006; 339: 88-95.

20. Khalifa NM, Al-Omar MA, Amr Ael-G, Haiba ME. HIV-1 and HSV-1 virus activities of some new polycyclic nucleoside pyrene candidates. Int J Biol Macromol 2013; 54: 51-56.

21. Abdel-Wahab BF, Mohamed SF, Amr AE, Abdalla MM. Synthesis and reactions of thiosemicarbazides, triazoles, and schiff bases as antihypertensive a-blocking agents. Monatshefte fur Chemie 2008; 139: 1083-1090.

22. Reichert LE, Bhalla VK. Development of a radioligand receptor assay for human follicle stimulating hormone. Endocrinology 1974; 94: 483-491.

23. Cheng KW. A radioreceptor assay for follicle-stimulating hormone. J Clin Endocrinol Metab 1975; 41: 581-589.

24. Andersen TT, Curatolo LM, Reichert LE Jr. Follitropin binding to receptors in testis: studies on the reversibility and thermodynamics of the reaction. Mol Cell Endocrinol 1983; 33: 37-52.

25. Reichert LE. Follicle-stimulating hormone: measurement by a rat testes tubule receptor assay. Methods in Receptor Research. Part I, Marcel Dekker, Inc., New York and Basel 1976; 99-118.

26. Foulds LM; Robertson DM. Electrofocusing Fractionation and Characterization of Pituitary Follicle-Stimulating Hormone From Male and Female Rats. Mol Cell Endocrinol 1983: 31: 117-130.

27. Ryle M. The activity of human follicle-stimulating hormone preparations as measured by a response in vitro. J Endocrinol 1971; 51: 97-107.

28. Boggins J; Ryle M. An in-vitro procedure for the quantitative measurement of follicle-stimulating activity. J Endocrinol 1972; 54: 355-356.

29. Steelman SL, Pohley FM. Assay of follicle stimulating hormone based on the augmentation with human chorionic gonadotropin. Endocrinology 1953; 53: 604-616.

30. Marana R, Robertson DM, Suginami H, Diczfalusy E. The assay of human follicle-stimulating hormone preparations: the choice of a suitable standard. Acta Endocrinol 1979; 92: 599-614.

31. Zaidi AA, Robertson DM, Diczfalusy E. Studies on the biological and immunological properties of human follitropin: profile of two international reference preparations and of an aqueous extract of pituitary glands after electrofocusing. Acta Endocrinol 1981; 97: 157-165.

32. Burgon PG, Robertson DM, Stanton PG, Hearn MTW. Immunological activities of highly purified isoforms of human fsh correlate with in vitro bioactivities. J Endocrinol 1993; 139: 511-518. 
Follicle-stimulating hormone (FSH) activities of some synthesized isoxazole and pyrazoline derivatives

\section{*Correspondence to}

Ahmed A. Fayed

Respiratory Therapy Department

Taibah University

Saudi Arabia 